\section{University of Saskatchewan Linear Electron Accel- erator}

THE Canadian National Research Council and the University of Saskatchewan Board of Governors have recently made available funds to the Department of Physics, University of Saskatchewan, for a linear electron accelerator and the erection of a building to house this machine and provide the ancillary research space. Preliminary plans indicate that it will be a travelling wave machine composed of six separate accelerating sections each about 4.8 metres long operating in the $2 \pi / 3, T M$ mode. These will be powered by three $S$-band $(2,856 \mathrm{Mc}$./s. $)$ klystron amplifiers of the type to be used on the 2-mile linear accelerator of Stanford University (Project $M$ ). Each klystron, delivering approximately $26 \mathrm{MW}$. peak and $22 \mathrm{~kW}$. radio-frequency power average, has two output windows and will thus feed two of the accelerator sections. An unloaded (zero beam current) energy of $250 \mathrm{MeV}$. is anticipated, and, when loaded to deliver $20 \mathrm{~kW}$. of beam power, the energy should be in excess of $150 \mathrm{MeV}$. Single shot operation is specified as well as repetition-rates up to $1,400 \mathrm{c} . / \mathrm{s}$.

One feature of this machine will be the availability of exceedingly narrow pulses at the higher repetitionrates. Widths of $10 \mathrm{musec}$. are being specified in the design, although according to recent technological advances pulses as narrow as 1 musec. are confidently expected. The beam current in the narrow pulse is expected to exceed 2 amp. Pulse widths may, however, be varied up to $l$ usec. with correspondingly lower repetition-rates. Since the $S$-band machine operates at $3 \times 10^{9} \mathrm{c} . / \mathrm{s}$. and the electrons are bunched on the crest of each cycle with a phase spread of $20^{\circ}$, the electron beam is composed of individual electron bunches each $2 \times 10^{-11}$ sec. in duration with $\frac{1}{3}$ musec. spacing between them. A l-musec. pulse, as mentioned here, will thus be composed of 3-5 such bunches, each carrying 25 amp., that is, each bunch is $\frac{1}{2} \mathrm{~cm}$. diameter, $\frac{3}{4} \mathrm{~cm}$. long and contains $3 \times 10^{9}$ electrons. The energy of the electron beam will be continuously variable from $5 \mathrm{MeV}$. to the maximum value of $250 \mathrm{MeV}$. Experiments in nuclear physics and radiation chemistry are being planned. Intense beams of photons, electrons and neutrons will be available for these.

\section{Australian National Insect Collection}

Over the past thirty years the Division of Entomology of the (Australian) Commonwealth Scientific and Industrial Research Organization has been building up a collection of insects drawn from all States and Territories of the Commonwealth. Intensive collecting by officers of the Division has been supplemented by numerous major donations and bequests, and to-day the collection is unquestionably the largest and most representative in existence of the insects of Australia and her dependent territories. By proclamation in the Commonwealth Gazette, the collection has been named the Australian National Insect Collection in order to emphasize its status as a national heritage which it is the responsibility of the Commonwealth to preserve in perpetuity for scientific study. The title establishes an Australian equivalent of the Canadian and South African National Insect Collections and is to be welcomed for the assurance it implies regarding the future of the Collection. The Collection will remain for the present in the custody of the Division of Entomology in Canberra, where it will play its part in the Division's research programme. Co-operation with Australian and overseas museums will continue as in the past.

\section{The National Foundation for Scientific Research, Brussels}

THE thirty-fourth annual report of the National Foundation for Scientific Research, Brussels, for 1960-61 (Pp. 384. Bruxelles: Fonds National de la Recherche Scientifique, 1962), records the award of 104 research grants totalling $9 \cdot 3$ million francs to individual investigators, varying in amount from 25,000 to 200,000 francs. Seventeen grants for special research work in the academic year 1961-62, totalling $11,308,088$ francs, were also made and five extraordinary awards for 1960-61, amounting to $11,349,000$ francs. These include 2.25 million francs for the determination of coefficients of diffusion in alloys; 625,000 francs for an experimental study of the irreversible phenomena of relaxation of nuclear magnetism; 426,125 francs for a structural study of new amino-acids produced by different vegetables and fungi, including the isolation, determination of structure and synthesis of antibiotics; 750,000 francs for a study of high dispersion in the infra-red absorption spectra of vinyl and ethylene isotopes; 957,500 franes for the construction of an ultra-violet spectro. graph of very high power; 994,845 francs for the purchase of apparatus for the study of electronic resonance in irradiation by $\mathbf{X}$-rays in polymerization and in the radiolysis of organic liquids and alcohols in the solid state; 677,500 franes for the study of natural products, including indolic alkaloids, erythrophleums and Morinda lucida; 1,262,158 francs for the study of constructional materials in which deformation has an important influence in their behaviour in fatigue (including concrete, wood and plastics); and 588,900 francs for studies of the toxicology of pharmaceutical products, including the identification of metabolites and the standardization of pharmaceutical preparations based on enzymes. A subsidy of 8 million francs was awarded to the Foundation for Scientific Medical Research for investigations on radioisotopes and cancer. Other grants were made to assist attendance at scientific meetings in other countries. Lists of awards are appended to the report, together with a list of publications by recipients of awards, 1958-61.

\section{Health in India}

ON June 12, 1959, the Government of India set up a committee to review development in all matters relating to health and to formulate plans for the country in the third and subsequent Five-Year Plan periods. The chairman was Dr. A. Lakshmanaswami Mudaliar, vice-chancellor of the University of Madras, who, with his distinguished colleagues, has now presented a report which should form a basis for improving health services in India for many years to come. Even on such controversial issues as the limiting of population growth and the indigenous systems of medicine, the committee is clear and firm in its recommendations. With all its implications for the future of India, the way in which the report has been prepared and presented merits praise; it could be read with profit by many health administrators outside India (Government of India: Ministry of Health. Report of the Health Survey and Planning Committee (August 1959-October 1961), Vol. 1. Pp. 482+56. Delhi: Government of India-Ministry of Health, 1962). 